\title{
The Choice of Titling System in Land*
}

\author{
Benito ARRUÑNADA ${ }^{\dagger}$ \\ Universitat Pompeu Fabra
}

\author{
Nuno GAROUPA \\ Universidade Nova de Lisboa \\ CEPR, London
}

December, 2004

*We have benefited from comments by one anonymous referee, the editors Sam Peltzman and George Triantis, and suggestions by Robert Ellickson, Hans-Bernd Schäfer, CF Sirmans, Charles Ward, and seminar participants at Hamburg University, Universitat Pompeu Fabra, and at the Third Maastricht-Cambridge Symposium. This work has received financial support from the MCYT, an agency of the Spanish Government, through grant SEC2002-04471-C02-02. The usual disclaimers apply.

${ }^{\dagger}$ Department d'Economia i Empresa, Universitat Pompeu Fabra, Ramon Trias Fargas 25-27, 08005 Barcelona, Spain. Phone: 34-93-5422572. Fax: 34-93-5421746. Email: benito.arrunada@upf.edu

${ }^{\ddagger}$ Faculdade de Economia, Universidade Nova de Lisboa, Campus de Campolide, P1099-032 Lisboa, Portugal. Phone: 351-21-3801600. Fax: 351-21-3870933. Email: ngaroupa@fe.unl.pt 


\begin{abstract}
This paper analyzes the choice of the socially optimal titling system assuming rational individual choices about recording, assurance and registration decisions. It focuses on the enforcement of property rights on land under private titling and the two existing public titling systems, recording and registration. When the reduction in the expected costs of forfeiture balances the higher cost of initial registration, a registration system is more efficient than a recording system. Implications for title assurance, land improvements and transactions are also considered.
\end{abstract}

Keywords: land transfer, registration, recording, property rights, title assurance, insurance, adverse selection.

JEL literature: K11, K12, L85. 


\section{Introduction}

The functioning of titling systems in land holds important consequences for the economy. Investments in land are affected by the security of property rights. Furthermore, land is relatively unmovable so it provides good collateral. Well functioning titling systems therefore promote investment and reduce the transaction cost of credit. This was well understood by reformers in the 19th century, when the transition from a system of privacy of property rights to one of publicity, either of deeds or rights, was hotly discussed. ${ }^{1}$ Knowledge on the design of these systems has again become crucial with the attempts (and repeated failures) to lay out the institutional foundations of markets in developing and transition economies. As an influential writer suggests, developed societies may have forgotten the blueprints of their basic institutions in this field. ${ }^{2}$ This article, in tandem with previous work by Arruñada $(2002,2003)$, aims to explain their structure.

Legally, 'property rights' are rights in rem, enforced by the courts by applying a rule of property. ${ }^{3}$ Right holders are thus protected against future actions by other people. They are, however, uncertain about the quality of their title, given that it can be defeated if someone with a better title appears. ${ }^{4}$ For instance, an owner is protected against fraudulent conveyance

\footnotetext{
${ }^{1}$ See Arruñada (2003, p.432, n.75) for references on these discussions.

${ }^{2}$ See De Soto (2000).

${ }^{3}$ In the Calabresi and Melamed (1972) sense, who oppose property and liability rules even if not dealing with the in rem nature of property. When rights on land are enforced as property rights, they are claimable against the asset itself and are therefore valid against all persons. They are said to 'run with the land,' meaning that they survive unaltered through all kinds of transactions and transformations dealing with other rights on the same or neighboring parcels. For example, the mortgagee keeps the same claim on the land even after the mortgagor sells it. By contrast, contractual rights are enforced only against a specific person. See also a series of works focusing mainly on the constraints that legal systems impose on their creation, the so-called 'numerus clausus' problem; Heller (1998, 1999), Buchanan and Yoon, (2000), Merrill and Smith (2000, 2001a, 2001b), and Hansmann and Kraakman (2002).

${ }^{4}$ The term 'title' may refer to a legal right, as here, or to the evidence of it, often a
} 
of her land but may lose the land if she bought it from someone who lacked good title and the legal owner claims it.

This article compares how different legal systems solve this problem, reducing the uncertainty of property rights. We use as the benchmark a regime of 'privacy', under which the courts enforce property rights in rem even if they have remained hidden. To the extent that consent of affected right holders (legal owners but also mortgagees, neighbors, public authorities and so $\mathrm{on}^{5}$ ) is frequently impossible to gather ex ante, because of lack of information on hidden conflicting rights, most rights remain subject to substantial uncertainty. They face the risk that a competing property right might emerge, transforming them into contractual rights so that they conflict with the previously hidden rights.

For this reason, modern legal systems only enforce as property rights those for which either titles or rights themselves are made public, giving rise to the two systems that we will call 'recording' and 'registration'. ${ }^{6}$ Under recording (e.g., in France and the USA), courts solve conflicts by allocating property rights according to the date when the private contracts, the deeds, are filed in a public office. This encourages parties to record as soon as possible and makes it possible for parties and intermediaries to collect the consent of all affected right holders, voluntarily reducing titling conflicts. Under registration (including the Torrens version), private contracts also get provisional priority when they are lodged. However, the registrar, acting in a quasi-judicial capacity, only registers a right if no other rights are damaged or consent is given by any right holders affected. This mandatory requirement

deed. Any ambiguity is easily clarified by context.

'From now on we will use the terms 'ownership' and 'owner' to refer to the variety of property rights and right holders in real estate. Current owners are also assumed to be good faith third party acquirers. In addition, we will refer to the loss of the in rem standing of a right (caused, for example, by the loss of priority of a mortgage) as 'forfeiture' even if, strictly speaking, this term is only applicable to ownership.

${ }^{6}$ For sake of simplicity, we abstract from complementary systems, such as adverse possession, prescription, and quiet title suits. 
of consent removes potential defects and allows the legal system to consider registered rights as conclusive, changing the liability rule for those necessarily rare cases in which an error arises. Therefore, innocent third party acquirers are fully protected when they rely on the register, and keep the land even if a legal owner appears. A comparable process of gathering consent or 'purging' rights takes place under recording, made possible by the filing requirement and driven by the voluntary interest of acquirers. However, given the private and voluntary nature of such purging, the courts necessarily continue to apply a property rule for allocating property rights in case of title conflict.

In a series of articles, Miceli et al. model the consequences of using property and liability rules for solving title conflicts. ${ }^{7}$ Generally speaking, these models (in contrast, for example, with Janczyk, 1977) do not recognize that registration and recording face different costs and provide different benefits in terms of lowering the costs of forfeiture and uncertainty. Also, the finding that registration is efficient is driven by the assumption that the current owner values the land more than the claimant. Lastly, they do not consider privacy.

We solve these shortcomings by building a model that is closer to the production functions that experts claim the two systems are able to offer, with

\footnotetext{
${ }^{7}$ In particular, Miceli and Sirmans (1995), argue that (a) if transaction costs after adjudication are low (most notably, zero transaction costs), both recording and registration are efficient, that is, under both systems, the land ends up with the party who values it most; (b) if transaction costs are high and the current owner values the land more than the claimant does, registration is usually superior because it awards the land to the party who values it most; and (c) both the current and the legal owner prefer the system that awards each of them the land rather than monetary compensation equal to the market value. In a related work, Miceli, Sirmans and Turnbull (1998) argue in favor of the superiority of registration because it induces optimal investment on land improvement, whereas under recording investment is discouraged to the extent that returns on investment will probably be appropriated by the claimant. Furthermore, Miceli, Sirmans and Turnbull (2000) show that registration is more efficient than recording because the potential for legitimate adverse claims tends to inefficiently hasten land development in recording. In the long run, registration is more efficient because of gains in land improvements, even if the current owner values the parcel of land less than the claimant.
} 
registration incurring higher operating costs than pure recording (without assurance) but also providing higher benefits, and considering that owners have always the option of privacy. Moreover, we drop the restrictive assumption that current owners necessarily value land more than the claimants. We investigate if it is more efficient to implement recording or registration taking into account two main problems solved by land titling, enforcing property rights and reducing transaction costs. These more realistic assumptions produce highly relevant results, as we are able to reveal the hidden costs and benefits of each titling system, to predict how their comparative advantage is affected by exogenous changes, and to derive testable implications. In particular, our results suggest that, contrary to previous findings by Miceli et al., the relative efficiency of the different titling systems is unlikely to be resolved on purely theoretical grounds. More importantly, our model identifies the crucial dimensions for evaluating both systems empirically.

In our model, choosing recording rather than registration could be more efficient because we explicitly consider the possibility of privacy. Registration is more costly, hence some parcels of land that could be recorded if such a system was introduced, will remain in what we call privacy, that is, out of the public system of land titling, and not actually registered. In addition, the explicit consideration of titling assurance (title 'insurance' in the US) supports the argument because it is socially efficient to assure highly valuable parcels of land. While registration assures all registered parcels, recording with titling assurance only assures the most valuable parcels of land.

The paper goes as follows: in the next section, we discuss the problem of rights enforcement. Extensions of the model (title assurance, land development, and the problem of transaction costs) are considered in section 3 . Final remarks conclude the paper. 


\section{The Problem of Rights Enforcement}

In this section, we model individual titling decisions and social choice of the optimal land titling system in the presence of uncertainty about the legal quality of titles, assuming that sellers and buyers have the same information about title quality, an assumption that will be dropped in subsection 3.3. We start by considering three classes of titling system for dealing with title claims, leaving the possibility of title assurance until subsection 3.1.

We consider the possibility of keeping property rights private as an alternative to titling systems, both of which make property rights public. We assume that current owners do not necessarily record or register their titles, but may instead rely on keeping them private. Their decision will depend on a trade-off of individual costs and benefits. We then model the social decision to introduce a titling system assuming this individual freedom to record or register. ${ }^{8}$ We also assume that more costly titling systems reduce expected forfeiture costs more significantly; as well as a higher incidence of claims under recording than under registration, an assumption that is supported by empirical evidence.

\subsection{Individual Choice}

In a perfect world, with no uncertainty and no conflicting claims, the value of a parcel of land would be $V$. This value will be lower in the real world,

\footnotetext{
${ }^{8}$ This freedom is commonly found in reality except in the few jurisdictions in which registration is required to create or transmit property rights. The extent of this freedom most commonly depends on the willingness of the law or the courts to grant property, in rem, status to unrecorded or unregistered possessory rights, which is often done in a fuzzy way, with the courts imposing strict requirements for a third party acquirer to be considered in good faith. This fuzziness justifies our assumption about the higher incidence of claims under privacy. For a more detailed analysis of the scope for free choice under these systems, see Arruñada (2003, pp. 428-432). Registration and recording are usually compulsory, however, for abstract rights, such as mortgages, in all jurisdictions.
} 
however. Let $\theta$ be the marginal reduction of the private value of land due to expected costs of forfeiture, which is common knowledge for sellers and buyers. ${ }^{9}$

We consider three different classes of system for land titling. Under privacy, the marginal expected cost of forfeiture is $\theta_{0}: 0<\theta_{0}<1$. If the current owner does not record or register the deeds, the expected value of ownership would be $\left(1-\theta_{0}\right) V$, where the expected cost of forfeiture is $\theta_{0} V$ (see Figure 1). ${ }^{10}$

\section{$<$ INSERT FIGURE 1 HERE $>$}

Under recording, the marginal expected cost of forfeiture is $\theta_{1}: 0<\theta_{1}<$ $\theta_{0}<1$, and the expected value of ownership would then be $\left(1-\theta_{1}\right) V-R$, where $R$ is the private cost of recording, including the explicit price as well as other implicit costs. We assume that the marginal cost of forfeiture is

\footnotetext{
${ }^{9}$ Forfeiture costs include potential loss of the land for its current owner, transaction costs in future transactions, including those incurred to make transactions possible and opportunity losses from transactions that will not take place due to the remaining uncertainty, all costs measured in probabilistic terms (this would therefore include the 'demoralization' costs considered in Michelman's (1967) seminal work). We model these forfeiture costs as a percentage of the value of the land. Implicitly, we therefore assume that forfeiture costs exhibit constant returns to scale, thus the marginal expected cost of forfeiture is constant within a given titling system. Presumably, higher valued parcels of land are in fact subject to a higher probability of forfeiture for a given level of title assurance, thus incurring a higher marginal expected cost of forfeiture. Consideration of this characteristic would make the exercise more cumbersome, but there is no reason to think that the results obtained should not replicate those we suggest.

${ }^{10}$ The marginal expected cost of forfeiture under privacy is assumed to be independent of the titling system chosen by the government. Explicitly considering this dependence in the model would only modify the value of social welfare but not the observed fundamental divergence between the private and social motives for recording or registering land. Furthermore, it is unclear in which direction such dependence should go. On the one hand, one might be tempted to argue that privacy benefits from the existing public system, that is, that it free rides on the more effective public system (through a mechanism of general deterrence of claims, for instance). On the other hand, the stronger effects of public titling may be abused to fabricate claims on private titles. For instance, if neighboring land is registered rather than recorded, an owner should check that its boundaries are correctly defined.
} 
greater under privacy, that is, $\theta_{1}<\theta_{0}$, because recording eliminates some claims which might be possible; in particular, those originated by any subsequent deeds granted by the former grantor. The choice between privacy and recording is determined by comparing the cost of recording, $R$, with this gain from reducing the marginal expected cost of forfeiture, $\left(\theta_{0}-\theta_{1}\right) V$.

Under registration, the marginal expected cost of forfeiture is given by $\theta_{2}: 0<\theta_{2}<\theta_{1}<\theta_{0}<1$. The owner will then get $\left(1-\theta_{2}\right) V-Q$, where $Q$ is the private cost of registration, including the explicit price as well as other implicit costs. The marginal expected cost of forfeiture in registration is not zero because even if, under registration, owners in good faith do not suffer any forfeiture risk linked to former claims, they still suffer some chance of losing their property because of a registration mistake in the future. ${ }^{11}$

As Figure 1 shows, if the three options are available, an individual owning land of value $V$ would rely on privacy when the land is not very valuable, would record if its value is within a given interval, and would register if the land is highly valuable. ${ }^{12}$ Also note that the difference between the fortyfive degree line (utility in the perfect world) and the expected utility for the preferred titling system is greater for higher land values. ${ }^{13}$ In particular,

\footnotetext{
${ }^{11}$ Nevertheless notice that greater effectiveness of registration in reducing the marginal expected cost of forfeiture is also supported by the consideration that, without a very low probability of forfeiture for legal owners, the use of a liability rule becomes unsustainable. With a substantial number of failures, the application of a liability rule bankrupts the registration system to the extent that it is eventually abolished (as was the case with the Torrens registers in many US jurisdictions).

${ }^{12}$ In Figure 1, it is assumed that $\left(\theta_{0}-\theta_{2}\right) R<\left(\theta_{0}-\theta_{1}\right) Q$. Otherwise, recording is never preferred.

${ }^{13}$ Owners choose between the available titling options according to the present value of law, which incorporates expectations of future value. Individual titling choices are bound to become outdated as prices move up or down, but in an asymmetric fashion: while owners of revaluated land could easily 'title up,' owners of depreciated land cannot title down (choosing privacy) and would have therefore invested too much in recording or registering their now depreciated land. Two qualifications are in order. First, this loss would be short-lived because right holders would return to privacy for future transactions so their losses would be limited to the costs sunk in one instance of publicity. Second,
} 
given that individuals are assumed to be risk neutral, any current owner of land valued $V$ would prefer privacy if $\left(\theta_{0}-\theta_{1}\right) V<R$ and $\left(\theta_{0}-\theta_{2}\right) V<Q$; recording if $\left(\theta_{0}-\theta_{1}\right) V>R$ and $\left(\theta_{1}-\theta_{2}\right) V<Q-R$; registration otherwise.

\subsection{Social Choice}

The enforcement of land claims generates not only private but also social costs when transferred from current owners to rightful claimants (in privacy and recording) or from current owners to wrongful owners (in registration). The possibility of these nonconsensual transfers is socially costly because they trigger rent-seeking and, generally, transaction costs, especially to make future consensual transactions possible and to protect against fraud. ${ }^{14} \mathrm{We}$ assume that these social costs are a percentage of the private cost of forfeiture, $\lambda$, such that $0<\lambda<\infty$. $^{15}$

given the higher cost of registration, the loss would be greater under registration.

${ }^{14}$ For instance, real resources are spent in fabricating frauds and litigating disputes on current ownership. Also, future land sales become more difficult when titles are unclear. Furthermore, our rationale is applicable to all kinds of property rights, even those in which possession plays no role (as in mortgages), rather than only to ownership. Nor does our model rely on particular assumptions about who indemnifies the losing party (that is, the wrong owner under recording, the legal owner under registration). From a social viewpoint, it is not important because we consider social welfare in a purely utilitarian way (thus, the indemnification to the losing party is cancelled out by the payment made by the winning party). From an individual viewpoint, we can interpret the loss from forfeiture as a loss after indemnification.

${ }^{15}$ In general, we would expect $\lambda<1$ since individuals will typically bear a higher expected private cost than the expected social cost (amongst other reasons, because a transfer of land benefits other individuals in the economy). However, for technical completeness, we allow for the possibility that $\lambda \geq 1$; so the possibility that forfeiture might generate substantial rent-seeking is considered. Also notice that our rationale is analytically equivalent, but does not rely on, the assumption made by Miceli et al. (1998) whereby current owners value land more than claimants. In other words, both rationales are formally similar but ours is grounded on costs instead of preferences. More importantly, in Miceli et al.(1998), this assumption is critical for deriving the result that a registration system is more efficient than a recording system. In our model, when $\lambda=0$, the socially optimal titling system is privacy since both recording and registration generate costs and no benefit. Later on, when land improvements are considered as in subsection 3.2. below, that is 
To identify the social optimum, let us suppose that in a given economy the value of land $V$ is distributed with a probability density function $f(V)$, and a cumulative density function $F(V)$ in the interval $[0, \bar{V}]$, and let us normalize the quantity of land to one. In each titling system, social welfare is given by the social value of the parcels of land which remain under privacy and those whose titles are filed in the available public titling system. This aggregated value is given by the area below the broken lines represented in Figures 2 and 3 for privacy and either recording or registration.

\section{$<$ INSERT FIGURE 2 HERE $>$}

\section{$<$ INSERT FIGURE 3 HERE $>$}

When the government chooses recording, social welfare is given by two integrands representing the social net benefits from privacy and recording, where $r$ is the social cost for recording land:

$$
W^{r c}=\int_{0}^{R /\left(\theta_{0}-\theta_{1}\right)}\left(1-\theta_{0} \lambda\right) V d F(V)+\int_{R /\left(\theta_{0}-\theta_{1}\right)}^{\bar{V}}\left[\left(1-\theta_{1} \lambda\right) V-r\right] d F(V)
$$

Similarly, when the government chooses registration, social welfare is given by two integrands representing the social net benefits from privacy and

no longer true. When $\lambda$ is zero, privacy is not necessarily superior because the incentives for land improvement are diminished. 
registration, where $\rho>r$ is the social cost of registering land ${ }^{16}$ :

$$
W^{r g}=\int_{0}^{Q /\left(\theta_{0}-\theta_{2}\right)}\left(1-\theta_{0} \lambda\right) V d F(V)+\int_{Q /\left(\theta_{0}-\theta_{2}\right)}^{\bar{V}}\left[\left(1-\theta_{2} \lambda\right) V-\rho\right] d F(V)
$$

Social welfare is maximized when prices of recording and registration equal their respective social cost, that is, $R=r / \lambda$ and $Q=\rho / \lambda$. Given that the social cost of registering land $\rho$ is greater than the social cost of recording $r$, that is, $\rho>r$, the price for registration should be higher than the price for recording. ${ }^{17}$

More importantly, in both recording and registration, prices should be higher than individual marginal costs as long as social costs are positive but

\footnotetext{
${ }^{16}$ The variable cost of each system is explicitly included, assuming that the marginal cost of registration is higher than that of recording. This is consistent with the assumed probabilities of forfeiture under the two systems. In choosing this set of assumptions, our purpose is to model the essential features of the different titling technologies (that is, their different costs and effectiveness in reducing title uncertainty). Assumptions about costs and effectiveness are, of course, open to criticism. We have endeavored to introduce in the model the parametric differences we think are generally accepted in the literature. The scant empirical evidence available also supports that registration incurs higher costs but reduces the probability of forfeiture more than recording does (Janczyk 1977; Shick and Plotkin 1978; Miceli et. al. 2002). Nevertheless we must recognize that we assume that the costs of both recording and registration do not vary with land value and that the prices charged for both kinds of service also remain constant with land value. However, the results should not be affected by this assumption because, were we to allow costs to vary with land value, prices would also vary with land value. In this case, we should look for the appropriate two-tier tariff (which is usually applied in practice), instead of the fixed prices. Finally, there are no fixed costs related to the (first time) creation of registration or recording offices. Only variable costs are considered. Creating a registration system is surely more costly than a recording system, but this cost difference lies mainly in greater variable costs at the time of initial registration, not in the fixed costs of starting up the system. When title assurance is added to recording, it may even incur larger fixed costs than registration, due to the duplication of title plants (Arruñada, 2002).

${ }^{17}$ Notice, however, that if we had taken the view that registration and recording differ not only in the marginal expected cost of forfeiture, $\theta$, but also in the social cost incurred, $\lambda$, this conclusion would not necessarily hold because, for example, the stricter numerus clausus required by registration. Also, in subsection 3.2. when we consider land improvements, a different result would be obtained since registration generates more capital improvements and thus is socially more beneficial.
} 
lower than individual costs (that is, $0<\lambda<1$ ) because current owners do not take into account that, if a claim takes place, the social loss is less than the private loss. ${ }^{18}$ Thus, owners will file titles that, from a social standpoint, would better remain private.

The choice between recording and registration should be based on comparing $W^{r c}$ and $W^{r g}$. Because privacy is a viable alternative, whatever the titling system, adopting recording or registration as the titling system not only places land in one or the other titling system, potentially causing overand under-assurance (the second term in both expressions, (1) and (2)), but also leads owners to move their land out of the titling system and into privacy, generating a crowding-out effect (the first term in both expressions, (1) and (2)). For each, recording and registration, there is a breakeven point in terms of land value such that an individual is indifferent between relying on privacy or on the public system. Notice that it is not clear which of the two breakeven points is higher.

In particular, let us define $V_{0}=r /\left[\lambda\left(\theta_{0}-\theta_{1}\right)\right]$ and $V_{1}=\rho /\left[\lambda\left(\theta_{0}-\theta_{2}\right)\right]$, which are the socially optimal critical land values, conditional on optimal pricing, at which there is no difference for the marginal current owner between keeping the title under privacy or, respectively, recording or registering it. Notice that it is not clear which of the two critical values is higher. The price for initial registration is higher than that of recording, but the reduction in the marginal expected cost of forfeiture is also higher under a registration system than under a recording system.

\footnotetext{
${ }^{18}$ We have here a version of the familiar problem of excessive level of care when private benefits are higher than social benefits. See, for example, Shavell (1997).
} 
If recording has the lowest critical value $\left(V_{0} \leq V_{1}\right)$, recording should be preferred to registration if and only if it produces greater social welfare:

$$
\begin{aligned}
W^{r c}-W^{r g}= & \int_{V_{0}}^{V_{1}}\left[\left(\theta_{0}-\theta_{1}\right) \lambda V-r\right] d F(V) \\
& +\int_{V_{1}}^{\bar{V}}\left[\left(\theta_{2}-\theta_{1}\right) \lambda V+\rho-r\right] d F(V) \geq 0
\end{aligned}
$$

However, if registration has the lowest critical value $\left(V_{0}>V_{1}\right)$, recording is never preferred to registration because:

$$
\begin{aligned}
W^{r c}-W^{r g}= & \int_{V_{1}}^{V_{0}}\left[\left(\theta_{2}-\theta_{0}\right) \lambda V+\rho\right] d F(V) \\
& +\int_{V_{0}}^{\bar{V}}\left[\left(\theta_{2}-\theta_{1}\right) \lambda V+\rho-r\right] d F(V)<0
\end{aligned}
$$

The second and last terms in (3) and (4) refer to the parcels of land that will be recorded in a recording system and registered in a registration system, that is, those that will be inside the system.

The first term in (3) and (4) has similar interpretations, but with different implications. In (3), it is the net increase in value associated with the parcels of land that will be recorded in a recording system and just under privacy in a registration system. However, in (4), the first term refers to land that will be under privacy in a recording system and would have been registered if a registration system were available.

In (3), the first term is positive: a recording system is better for these parcels of land because, under a registration system, they are only subject to privacy (they are out of the system). The last term is very likely to be negative if the more valuable parcels tend to be registered rather than recorded, as it would be if they incur higher transaction costs, which seems likely. Thus, if the first term dominates the second, the condition in (3) is satisfied and recording is socially preferred to registration. 
We obtain an unambiguous result for (4). The first term is now negative: a registration system is better for these parcels of land because, under a recording system, owners prefer to rely on privacy without entering the public titling system. The last term is also negative for the same reason: they have to use recording when it would be worthwhile to register. In this case, registration is unambiguously preferred to recording.

In Figure 2, recording has the lowest breakeven point. There are parcels of land that would be inside the system with recording but outside the system under registration. Area $A$ is land that would be optimally recorded, but remains under privacy in registration; area $B$ is land that would be optimally recorded, but is registered in registration; and area $C$ is land that would be optimally registered, but remains recorded in recording. Figure 3 shows the opposite situation, where registration has the lowest breakeven point. Area $D$ is land that would be optimally registered, but its owners rely on privacy under recording; and area $E$ is land that would be optimally registered, but is recorded. ${ }^{19}$

\section{$<$ INSERT TABLE 1 HERE $>$}

\section{$<$ INSERT TABLE 2 HERE $>$}

Tables 1 and 2 identify the welfare gains and losses for each set of parcels of land. Clearly, $D$ plus $E$ is strictly positive, however $C$ minus $A$ minus $B$ could be negative, depending on the relative magnitude of $A$ plus $B$ and $C$. The socially preferred titling system is registration if $C>A+B$, and recording if $C<A+B$.

Our result means that recording may be socially preferable to registration

\footnotetext{
${ }^{19}$ These welfare gains would be affected by changes in land value. A general increase in value would be equivalent to moving the whole distribution of land to the right of Figure 2, increasing area $C$ and making registration preferable. This could account for the dominant move of developed countries from both privacy (England) and recording (Scotland, parts of Canada) towards registration or improved recording (France and even the US, when considering private title plants).
} 
for two reasons, both of them disregarded in the previous literature. The first is the higher marginal cost of registration over recording. The second that, because registration is more costly, some parcels of land that would be recorded under recording would remain privately titled, so missing the benefits of publicity under registration. ${ }^{20}$

\section{Extensions}

We extend here the previous analysis to consider title assurance, land development, and transaction costs, showing how these three aspects may affect the basic results derived before.

\subsection{Title Assurance}

In the basic model, we ignored the possibility that current owners can buy 'title assurance' services, understood as the private production of information and contractual services that reduces the probability of forfeiture. ${ }^{21}$ We will consider title assurance only under recording because, in essence, it is less necessary under registration and less viable under privacy. ${ }^{22}$

\footnotetext{
${ }^{20}$ Note also why such an important result could not be reached by Miceli et al. (1998). For them, recording is always inferior because they assume cost-free titling $(r=\rho=0)$ and, more critically, they disregard the possibility of privacy.

${ }^{21} \mathrm{We}$ assume individuals are risk neutral. Thus, there is no risk motivation for insurance and no social cost from inefficient risk sharing. Hence we designate activities that reduce the probability of forfeiture as 'title assurance' rather than 'title insurance.'

${ }^{22} \mathrm{As}$ in Miceli et al. (1998), we take the view that title assurance makes little sense under registration since the registration itself provides full title assurance. This is so because, as analyzed by Arruñada (2002), the low level of title insurance sold in countries with registration merely spreads title risk whereas in countries with recording it aims to prevent such risks. In the case of privacy, we assume title assurance is unavailable because of the difficulties of producing information when hidden property rights are legally enforceable. This is also true as, for land under privacy, precedents of title insurance were limited to occasional provision of a general third-party guarantee against forfeiture and defective title
} 
The current owner of a parcel of land valued at $V$ who were offered the full range of institutional solutions would just rely on privacy when the land is not very valuable; would record if its value is within a given interval; would buy title assurance services if the land is valuable but not sufficiently so to justify registration; and would register if the land is highly valuable. See a more comprehensive model fully developed in appendix A.

The choice of assurance by individuals is not socially optimal because owners do not care about the benefit of involuntary land transferring (unless transaction costs are such that $\lambda=1$ ). Thus, an individual will choose more (when $\lambda<1$ ) or less (when $\lambda>1$ ) assurance than is socially desirable. Some tax or regulation of private pricing for assurance services is therefore needed to reach the socially optimal level. ${ }^{23}$

Under recording with title assurance, social welfare is no longer given by expression (1), but must take into account that some parcels of land will be recorded without title assurance while others will be recorded with title assurance. With respect to social welfare, title assurance introduces a benefit (the reduction in transaction costs due to forfeiture becomes less likely) and a cost (that of producing the assurance itself). However, under registration, social welfare is still given by expression (2), as before, since there is no private title assurance.

Assurance services somehow alleviate what is a main deficiency of pure recording: leaving titles on highly valuable land subject to too much uncertainty. Therefore, the possibility of title assurance improves the standing of recording as compared to registration and, in the spirit of Figure 3, it increases $A$ and $B$ and reduces $C$, thus making $A+B-C$ more likely to

insurance policies for specific and known risks (Arruñada 2002, 592-593).

${ }^{23}$ There is some casual evidence of special taxation. The industry is heavily regulated both in the USA and France. Special taxation takes the form of documentary, mortgage, and transaction taxes which are frequently associated with the use of assurance recording services. 
be positive. However, the final result hinges on the ability of the assurance technology to reduce the likelihood of forfeiture at a reasonable low cost. If this is possible, a recording system becomes less of a problem for the most valuable parcels of land thus diluting to some extent the major advantage of registration. If not, we might end up with no title assurance and a result very close to that of subsection 2.2. In addition, if corrective taxation is not well designed, a recording system with title assurance will suffer distortion caused by individuals who, not caring about the benefit of involuntary land transferring, tend to buy more than socially optimal assurance services.

\subsection{Land Development}

Most of the literature on property rights in land has been concerned with land investment and the nature and enforcement of such property rights. ${ }^{24}$ It is therefore important that our conclusions remain valid when capital improvements are considered. A short technical digression will show why. See a more comprehensive model fully developed in appendix B.

Parcels of land are worth more after being improved. If the level of capital improvements is $k$ and the cost of capital improvements (whatever the titling system) is $C(k)$, where $C^{\prime}>0$ and $C^{\prime \prime}>0$, the return on capital improvements is $(1+k) V$. For each titling system, the expected value of ownership would be $\left(1-\theta_{i}\right)(1+k) V-C(k)$, where $i=0,1,2$. The choice of improvements, $k_{i}$, is given by $\left(1-\theta_{i}\right) V=C^{\prime}\left(k_{i}\right)$, since the appropriate second-order condition is satisfied. By comparing the three first-order conditions, we can conclude that the private choice of improvements satisfies $k_{2}>k_{1}>k_{0}$. As we should expect, there will more investment in land if the parcel is registered than recorded or the deeds are kept private. As a consequence, a parcel of land worth $V$ will have different values after im-

\footnotetext{
${ }^{24}$ For example, see Feder and Feeny (1991); Anderson and Lueck (1992); Ellickson (1993); Besley (1995); Alston, Libecap and Schneider (1996); and Miceli et. al. (1998).
} 
provements, depending on how it is titled; it will be more valuable if it is registered rather than recorded or just held under privacy. This effect makes registration more suitable for encouraging land improvements.

A second important result is that the private choice of land improvements is not socially optimal, because individuals do not recognize the positive externality such improvements will have for potential claimants. Efficient land improvement for a given system of land titling should satisfy $\left(1-\lambda \theta_{i}\right) V=C^{\prime}\left(k_{i}\right)$ for $i=0,1,2$. There is over-investment in land improvement if $\lambda>1$, and under-investment if $\lambda<1$. Therefore, some sort of corrective policy would be needed to achieve socially efficient land improvement. If transaction costs from forfeiture are relatively low, investment would be subsidized, whereas if transactions costs are very significant, it would be taxed.

Thirdly, social welfare under recording or registration is no longer given by (1) and (2), but must include the gains and costs from land improvement. In addition, investment in land and, consequently, land value are higher for registered than for recorded land, and are lowest for land held under privacy. The possibility of land improvements therefore exerts two opposite effects. On one hand, registration becomes socially more valuable because it leads to more investment, thus making registration superior to recording. ${ }^{25}$ However, the cost of leaving land outside of the public titling system also becomes higher because investment is lowest for land held under privacy. When these two effects are combined, it is unclear how land improvements affect the possibility of registration being socially more efficient than recording.

\footnotetext{
${ }^{25}$ A similar conclusion is obtained by Miceli et. al. (1998).
} 


\subsection{The Problem of Transaction Costs}

A major feature of the literature on property rights is the importance of land titling for transactions. ${ }^{26}$ Creating the right incentives for voluntary transactions in land is important because, in order to guarantee efficiency, those who value land more should be able to buy from those who value it less. We also need to avoid involuntary transactions by which an individual who values the land more loses it to an individual who values it less.

In this section, we consider the possibility that the seller has better information than the buyer concerning the cost of forfeiture due to future claims. In terms of our model, this means that the different $\theta$ s are private information. The buyer knows that $\theta_{i}$ is distributed in a given interval, where $i=0,1,2$ stands for privacy, recording and registration respectively; and she offers a price $P$ to the seller in a competitive market. ${ }^{27}$ The expected payoff for a risk neutral seller is $P-\left(1-\theta_{i}\right) V^{S}$. Given the price $P$, the seller accepts the offer as long as $\theta_{i}$ is greater than $1-P / V^{S}$. Here we can see the adverse selection problem: For a given $P$ offered by the buyer, the seller is only willing to sell if the marginal cost of forfeiture (unknown to the buyer) is reasonably high. As a consequence, parcels of land with high quality title will not be traded. See a more comprehensive model fully developed in appendix $\mathrm{C}$.

Given the decision of the seller concerning whether or not to sell, the buyer will choose the price so as to maximize the expected payoff subject to zero profits. Consequently, the price $P$ will necessarily be below the value of the land for the buyer, it will decrease with the expected marginal cost of forfeiture due to future claims, and will be below the expected benefit for the seller for those parcels of land with low marginal cost of forfeiture (adverse

\footnotetext{
${ }^{26}$ See Arruñada (2003) and references therein.

${ }^{27}$ Therefore, a zero expected profit condition will be imposed as a 'participation constraint' for the buyer.
} 
selection).

Clearly, prices will be highest for registered, in between for recorded, and lowest for privately held land. Therefore, the adverse selection problem will be less marked for registered, in between for recorded, and most marked for privately held land. The rationale is the following: The expected marginal cost of forfeiture is higher for recorded than for registered land; as a consequence, the price offered by the buyer will be higher for registered than for recorded land. A lower price for recorded land drives the better (in terms of secure land title) parcels out of the market, and a higher price for registered land keeps some of the better parcels of land in the market.

The explicit inclusion of land transactions therefore creates two opposite effects. On one hand, registration becomes socially more valuable because there is less adverse selection and more transactions. On the other hand, the cost of leaving land outside of the public titling system also increases because adverse selection is highest under privately held land. When these two effects are combined, it is also unclear how the explicit consideration of land transactions will affect the possibility of recording being socially more or less efficient than registration.

\section{Conclusion}

In this article we have explored the choice of titling system for land, introducing well-established relations about the relative costs and effectiveness of three possibilities: private titling (that is, privacy) and the public titling systems of registration of rights and recording of deeds (the latter with and without 'private assurance' services, which may take the form of private title 'insurance').

In our model, once a public titling system is in place, owners choose to 
rely on public titling or to keep their rights private. Consequently, the social choice of title system is given by the net balance of the following effects: recording causes under-assurance of higher value land, while registration causes crowding out and over-assurance of lower value land. The net balance of these effects and, therefore, the optimal title system are determined by the relative cost effectiveness and pricing of titling (including private 'title assurance services'). Recording triggers under-assurance of land which is recorded under recording but, given its greater value, would be efficiently registered. Conversely, crowding out happens under registration because its higher price leads owners to keep private some lower value land which otherwise would have been recorded. Similarly, some mid-value land that would have been recorded under recording is registered under registration, causing over-assurance. These results are quite general, as they hold, with minor differences, for situations with and without private assurance services, land improvements and information asymmetry between sellers and buyers of land.

We acknowledge that our results are based on a stylized description of the different titling systems and are more relevant for jurisdictions with no public titling. In addition, we have focused on the ideal models of each system. For instance, assuming that title assurance under recording can never do better in terms of benefits than registration is probably true of the best examples of each system, but dysfunctional registration systems surely perform worse than good recording plus assurance. We think that this assumption, however, is not too restrictive for the problem we are modeling because performances of alternative systems within the same jurisdiction are likely to be positively correlated. The poor performance of registration systems which functioned simultaneously with recording, as the Torrens register did in Cook county, is not necessarily relevant for this discussion, because the simultaneous, not alternative, presence of both systems complicates the comparison with issues of adverse selection and additional rent seeking. 
Notwithstanding, our results hold important policy implications, which are consistent with institutional observations. First, whatever the titling system, the pricing of public titling and private assurance services above cost is essential for social efficiency because, as forfeiture has greater private than social costs, marginal cost pricing would produce over-assurance. This provides a justification for taxing land transactions, to the extent that this tax, which is often linked to public filing, acts as an above-cost price that limits owners' inclination to over-assure.

Second, the choice of titling system should consider the over- and underassurance and crowding out effects, as well as the possibility of avoiding them through both corrective pricing and/or intermediate legal solutions. In particular, the Government could limit the crowding out effect of registration by pricing titling services in a way that motivates owners of intermediatevalue land to register. More generally, our results provide a rationale for providing legal palliatives under both registration and recording, which avoid their specific disadvantages.

Both prescriptions find empirical support in the functioning of most titling systems, as all around the world private assurance is heavily regulated and taxed, reducing over-assurance, and land registers apply prices that increase with land value and include a fixed element, which might reduce crowding out and keep the lowest-value land under privacy. In addition, palliatives are also widespread. Recording systems often provide a simplified judicial procedure to clear title (the French purge and the American quiet title suit), a solution to the under-assurance of the most valuable land. Registration systems usually also allow some kind of inexpensive filing with lesser, or provisional, legal effects. This often takes the form of provisional registration of possessory title, which can be considered a form of recording within a register of rights and substantially reduces the crowding out and over-assurance effects. 
More generally, the article confirms that the choice of an efficient titling system is an empirical issue, which cannot be solved on purely theoretical grounds. It throws two doubts on the certainties that seem to inspire the huge efforts being made by international aid agencies in the development of land titling systems. First, it points to the division between the private and social benefits of title assurance activities. Second, it models the behavior of individuals opting out of filing systems, a common circumstance often forgotten in over-ambitious titling initiatives.

\section{References}

ALSTON, L. J., G. D. LIBECAP and R. SCHNEIDER (1996), "The Determinants and Impact of Property Rights: Land Title on the Brazilian Frontier," Journal of Law, Economics and Organization, vol. 12, no. 1, pp. 25-61.

ANDERSON, T. L., and D. LUECK (1992), "Land Tenure and Agricultural Productivity on Indian Reservations," Journal of Law and Economics, vol. 35, October, pp. 427-454.

ARRUÑADA, B. (2002), "A Transaction-Cost View of Title Insurance and its Role in Different Legal Systems," The Geneva Papers on Risk and Insurance-Issues and Practice, vol. 27 (3), July, pp. 582-611.

ARRUÑADA, B. (2003), "Property Enforcement as Organized Consent," Journal of Law, Economics and Organization, vol. 19, no. 2, pp. 401-444.

ARRUÑADA, B., and N. GAROUPA (2004), "The Choice of Titling System in Land," Universitat Pompeu Fabra Working-Paper no. 607.

BESLEY, T. (1995), "Property Rights and Investment Incentives: Theory and Evidence from Ghana," Journal of Political Economy, vol. 103, pp. 
903-937.

BUCHANAN, J. M., and Y. J. YOON (2000), "Symmetric Tragedies: Commons and Anticommons," Journal of Law and Economics, vol. 43, no. 1, April, pp. 1-13.

CALABRESI, G., and A. D. MELAMED (1972), "Property Rules, Liability Rules, and Inalienability: One View of the Cathedral," Harvard Law Review, vol. 85, pp. 1089-1128.

DE SOTO, H. (2000), The Mystery of Capital: Why Capitalism Triumphs in the West and Fails Everywhere Else, Basic Books, New York.

ELLICKSON, R. (1993), "Property in Land," Yale Law Journal, vol. 102, pp. 1315-1400.

FEDER, G., and FEENY, D. (1991), "Land Tenure and Property Rights: Theory and Implications for Development Policy," The World Bank Economic Review, vol. 5, pp. 135-153.

HANSMANN, H., and R. KRAAKMAN (2002), "Property, Contract, and Verification: The Numerus Clausus Problem and the Divisibility of Rights," Journal of Legal Studies, vol. 31, no. 2, pp. S373-S420.

HELLER, M. A. (1998), "The Tragedy of the Anticommons: Property in the Transition from Marx to Markets," Harvard Law Review, vol. 111, no. 3, pp. 621-688.

HELLER, M. A. (1999), "The Boundaries of Private Property," Yale Law Review, vol. 108, pp. 1163-1223.

JANCZYK, J. (1977), "An Economic Analysis of the Land Title Systems for Transferring Real Property," Journal of Legal Studies, vol. 6, pp. 213233. 
MERRILL, T. W., and H. E. SMITH (2000), "Optimal Standardization in the Law of Property: The Numerus Clausus Principle," Yale Law Journal, vol. 110, no. 1, October, pp. 1-70.

MERRILL, T. W., and H. E. SMITH (2001a), "The Property/Contract Interface," Columbia Law Review, vol. 101, no. 4, May, pp. 773-852.

MERRILL, T. W., and H. E. SMITH (2001b), "What Happened to Property in Law and Economics?," Yale Law Journal, vol. 111, pp. 357-398.

MICELI, T. J., and KIEYAH, J. (2003), "The Economics of Land Title Reform," Journal of Comparative Economics, vol. 31, pp. 246-256.

MICELI, T. J., MUNNEKE, H., SIRMANS, C. F., and TURNBULL, G. K. (2002), "Title Systems and Land Values," Journal of Law and Economics, vol. 45 , pp. 565-582.

MICELI, T. J., and SIRMANS, C. F. (1995), "The Economics of Land Transfer and Title Insurance," Journal of Real Estate Finance and Economics, vol. 10, pp. 81-88.

MICELI, T. J., SIRMANS, C. F., and J. KIEYAH (2001), "The Demand for Land Title Registration: Theory with Evidence from Kenya," American Law and Economics Review, vol. 3, pp. 275-287.

MICELI, T. J., SIRMANS, C. F., and TURNBULL, G. K. (1998), "Title Assurance and Incentives for Efficient Land Use," European Journal of Law and Economics, vol. 6, pp. 305-323.

MICELI, T. J., SIRMANS, C. F., and TURNBULL, G. K. (2000), "The Dynamic Effects of Land Title Systems," Journal of Urban Economics, vol. 47, pp. 370-389.

MICHELMAN, F. (1967), "Property, Utility and Fairness: Comments on the Ethical Foundations of 'Just Compensation' Law," Harvard Law Review, 
vol. 80,pp. 1165-1258.

SHAVELL, S. (1997), "The Fundamental Divergence between the Private and the Social Motive to Use the Legal System," Journal of Legal Studies, vol. 26, pp. 575-612.

SHICK, B., and PLOTKIN, I. (1978), Torrens in the United States: A Legal and Economic History and Analysis of American Land Registration Systems, Lexington MA, Lexington Books.

\section{Appendix A: Formal Model with Title Assur- ance}

A provider of title assurance investigates the standing of the title, reducing the likelihood of forfeiture. For a given level of effort, the marginal expected cost of forfeiture borne by the current owner is $\theta(n): 0<\theta_{2}<\theta(n)<$ $\theta_{1}<\theta_{0}<1$, where $n$ is effort (cost) to reduce the expected marginal cost of forfeiture, $\theta(0)=\theta_{1}, \lim _{n \rightarrow \infty} \theta(n)=\theta_{2}, \theta^{\prime}<0, \theta^{\prime \prime}>0$. The price for title assurance is $S$.

The expected value for a current owner who buys title assurance is ( 1 $\theta(n)) V-R-S$. Thus, an owner decides on title assurance if the gain $\left(\theta_{1}-\theta(n)\right) V$ is more than the cost $S$.

Easy computation allows us to $\mathrm{say}^{28}$ :

Any current owner of land valued $V$ would prefer:

(a) Privacy if $\left(\theta_{0}-\theta_{1}\right) V<R,\left(\theta_{0}-\theta_{2}\right) V<Q$, and $\left(\theta_{0}-\theta(n)\right) V<R+S$;

\footnotetext{
${ }^{28}$ It is assumed that $\left(\theta_{1}-\theta(n)\right) R<\left(\theta_{0}-\theta_{1}\right) S$ and $\left(\theta_{1}-\theta_{2}\right) S<\left(\theta_{1}-\theta(n)\right)(Q-R)$. Otherwise recording or title assurance would never be preferred because the prices to be paid would not be compensated for by the lower likelihood of forfeiture.
} 
(b) Recording if $\left(\theta_{0}-\theta_{1}\right) V>R,\left(\theta_{1}-\theta_{2}\right) V<Q-R$, and $\left(\theta_{1}-\theta(n)\right) V<S$;

(c) Recording with Title Assurance if $\left(\theta_{0}-\theta(n)\right) V>R+S,\left(\theta(n)-\theta_{2}\right) V<$ $Q-R-S$, and $\left(\theta_{1}-\theta(n)\right) V>S$;

(d) Registration if otherwise.

The profits for a provider of title assurance services are $S-n$ per parcel of land 'assured.' In a perfectly competitive market, we will have $S=n$ (zero profit constraint). Thus, the expected value for an owner who buys title assurance is $(1-\theta(n)) V-R-n$. The amount of assurance bought by an owner with a parcel of land valued $V$ is $n^{*}$ given by $-\theta^{\prime}\left(n^{*}\right)=1 / V$, where $n^{*}$ increases by $V$. Owners with more valuable parcels of land will want to buy more title assurance. Moreover, the likelihood of forfeiture is endogenous and varies negatively with $V$.

Define $V^{*}$ as $-1 / \theta^{\prime}(0)$. Obviously, owners for whom $V \leq V^{*}$ do not buy title assurance because it is not worthwhile for them to do so. On the other hand, owners for whom $V>V^{*}$ buy title assurance. We can think of $V^{*}$ as measure of assurance technology. The lower $V^{*}$, the more efficient the technology will be.

When a government chooses a recording system, social welfare is given by:

$$
\begin{aligned}
W^{r c}= & \int_{0}^{R /\left(\theta_{0}-\theta_{1}\right)}\left(1-\theta_{0} \lambda\right) V d F(V)+\int_{R /\left(\theta_{0}-\theta_{1}\right)}^{V^{*}}\left[\left(1-\theta_{1} \lambda\right) V-r\right] d F(V) \\
& +\int_{V^{*}}^{\bar{V}}\left[\left(1-\theta\left(n^{*}(V)\right) \lambda\right) V-n^{*}(V)-r\right] d F(V)
\end{aligned}
$$

where we assume that $V^{*}>r /\left[\lambda\left(\theta_{0}-\theta_{1}\right)\right]$, otherwise everyone who records necessarily buys title assurance. When a government chooses a registration system, social welfare is given by (2) as before, since there is no need for private title assurance. 
The socially optimal pricing vector $\langle R, Q>$ is the same as in section 2.2. The possibility of title assurance does not affect optimal pricing because the owner at the margin between recording and privacy does not buy assurance.

The choice of assurance by individuals is not socially optimal because owners do not care about benefits generated by involuntary land transferring (unless of course transaction costs are such that $\lambda=1$ ). Thus, an individual will choose more $(\lambda<1)$ or less $(\lambda>1)$ assurance than is socially desirable. Let us modify the expected value for an owner who buys title assurance to take into account taxation: $(1-\theta(n)) V-R-(1+t) n$, where $t$ is the tax rate. The amount of resources bought by an owner with a parcel of land valued at $V$ is now given by $-\theta^{\prime}\left(n^{*}\right) V=1+t$. Social welfare is the same as in (5) since taxes are assumed to be a (neutral) transfer from individuals to the government. It can be easily checked that the social optimal value for $n$ should satisfy $-\theta^{\prime}\left(n^{*}\right) V \lambda=1$. Consequently, the tax rate should be given by $-\theta^{\prime}\left(n^{*}\right)(1-\lambda) V$.

Positive taxation is socially optimal as long as $\lambda<1$, and negative taxation is socially optimal as long as $\lambda>1$. Moreover, the lower $\lambda$ is, the higher the tax rate will be. Another important observation is that owners of higher-valued land should pay higher taxes because the difference between the private value $(V)$ and the social value $(\lambda V)$ of assurance increases by $V$.

Once the appropriate tax rate is set, the individual choice of assurance is socially optimal. Furthermore, $V^{*}$ should be re-defined as $-1 /\left(\theta^{\prime}(0) \lambda\right)$. The measure of assurance technology is negatively affected by $\lambda$. The rationale is that, as $\lambda$ goes down, assurance becomes socially less valuable so fewer owners buy it, and $V^{*}$ should go up.

When modeling the choice made by a government which takes into account the possibility of private title assurance when deciding between recording and registration, there are three possible cases depending on the limits of integration. Define as before $V_{0}=r /\left[\lambda\left(\theta_{0}-\theta_{1}\right)\right]$ and $V_{1}=\rho /\left[\lambda\left(\theta_{0}-\theta_{2}\right)\right]$. 
If recording has the lowest critical value $\left(V_{0} \leq V_{1}<V^{*}\right)$, where assurance technology is highly inefficient and registration is relatively costly, recording should be preferred to registration if, and only if, it produces greater social welfare:

$$
\begin{aligned}
W^{r c}-W^{r g}= & \int_{V_{0}}^{V_{1}}\left[\left(\theta_{0}-\theta_{1}\right) \lambda V-r\right] d F(V)+\int_{V_{1}}^{V^{*}}\left[\left(\theta_{2}-\theta_{1}\right) \lambda V+\rho-r\right] d F(V) \\
& +\int_{V^{*}}^{\bar{V}}\left[\left(\theta_{2}-\theta\left(n^{*}(V)\right) \lambda V+\rho-r-n^{*}(V)\right] d F(V) \geq 0\right.
\end{aligned}
$$

However, if registration has the lowest critical value $\left(V_{1}<V_{0}<V^{*}\right)$, where registration is relatively inexpensive, recording is never preferred to registration because:

$$
\begin{aligned}
W^{r c}-W^{r g}= & \int_{V_{1}}^{V_{0}}\left[\left(\theta_{2}-\theta_{0}\right) \lambda V+\rho\right] d F(V)+\int_{V_{0}}^{V^{*}}\left[\left(\theta_{2}-\theta_{1}\right) \lambda V+\rho-r\right) d F(V) \\
& +\int_{V^{*}}^{\bar{V}}\left[\left(\theta_{2}-\theta\left(n^{*}(V)\right) \lambda V+\rho-r-n^{*}(V)\right) d F(V)<0\right.
\end{aligned}
$$

Yet, if recording has the lowest critical value $\left(V_{0}<V^{*} \leq V_{1}\right)$, where assurance technology is reasonably efficient and registration is relatively costly, recording should be preferred to registration if, and only if, it produces greater social welfare:

$$
\begin{aligned}
W^{r c}-W^{r g}= & \int_{V_{0}}^{V^{*}}\left[\left(\theta_{0}-\theta_{1}\right) \lambda V-r\right] d F(V) \\
& +\int_{V^{*}}^{V_{1}}\left[\left(\theta_{0}-\theta\left(n^{*}(V)\right) \lambda V-n^{*}(V)-r\right] d F(V)\right. \\
& +\int_{V_{1}}^{\bar{V}}\left[\left(\theta_{2}-\theta\left(n^{*}(V)\right) \lambda V+\rho-n^{*}(V)-r\right] d F(V) \geq 0\right.
\end{aligned}
$$

For low values of $V$, in both systems, land will just rely on privacy as seen before. Also, as in the basic model developed in the paper, for high values of $V$, land will be recorded with assurance in a recording system and registered in a registration system (last term in (6), (7) and (8)). It is for the intermediate range of values that we get different characterizations. 
In (6), land will be recorded without assurance in a recording system but will rely on privacy in a registration system (first term). For the following set of values, land will be recorded without assurance in a recording system and registered in a registration system (second term).

In (7), land will be registered in a registration system but will rely on privacy in a recording system (first term). For the following set of values, land will be recorded without assurance in a recording system and registered in a registration system (second term).

In (8), land will be recorded without assurance in a recording system but will rely on privacy in a registration system (first term). For the following set of values, land will be recorded with assurance in a recording system but still relying on privacy in a registration system (second term).

The expressions will depend on what happens for intermediate values, that is, whether or not we can get these parcels of land into the public land titling system.

In (6), the first term is positive: a recording system is better for these parcels of land because, under a registration system, only privacy takes place. The second and third terms are likely to be negative, because highly valuable parcels of land should be registered rather than recorded (with or without assurance). Thus, if the first term dominates the other two, recording is socially preferred to registration. Notice that this is the case we have described above as highly inefficient assurance technology and relatively costly registration. This case is also very similar to the first case in the basic model (when title assurance is not available), where (6) is similar to (3) when $V^{*}$ tends to $\bar{V}$.

In (7), the three terms are negative: registration is preferred to recording. This case is very similar to the second case in the basic model (when title assurance is not available), where (7) is similar to (4) when $V^{*}$ tends to $\bar{V}$. 
It is (8) that is new in some regards in comparison with the basic model. The first term is positive and the last term is negative as in (6). However, the second term could be negative or positive, depending on how much more expensive it is to record with assurance rather than just privately title. Thus, if the last term is dominated by the other two, recording is socially preferred to registration.

\section{Appendix B: Formal Model with Land Improve- ment}

Once we identify the private choice of land improvement after corrective taxation so that $\left(1-\lambda \theta_{i}\right) V=C^{\prime}\left(k_{i}\right)$ for $i=0,1,2$, we can define the limits of integration for social welfare implicitly because the choice of improvements depends on $V$ :

$$
\begin{gathered}
{\left[\left(1-\theta_{1}\right)\left(1+k_{1}\right)-\left(1-\theta_{0}\right)\left(1+k_{0}\right)\right] V_{0}=R+C\left(k_{1}\right)-C\left(k_{0}\right)} \\
{\left[1+k_{2}-\left(1-\theta_{0}\right)\left(1+k_{0}\right)\right] V_{1}=Q+C\left(k_{2}\right)-C\left(k_{0}\right)}
\end{gathered}
$$

When a government chooses a recording system, social welfare is given by:

$$
\begin{aligned}
W^{r c}= & \int_{0}^{V_{0}}\left[\left(1-\theta_{0} \lambda\right)\left(1+k_{0}\right) V-C\left(k_{0}\right)\right] d F(V) \\
& +\int_{V_{0}}^{\bar{V}}\left[\left(1-\theta_{1} \lambda\right)\left(1+k_{1}\right) V-r-C\left(k_{1}\right)\right] d F(V)
\end{aligned}
$$

When a government chooses a registration system, social welfare is given by:

$$
\begin{aligned}
W^{r g}= & \int_{0}^{V_{1}}\left[\left(1-\theta_{0} \lambda\right)\left(1+k_{0}\right) V-C\left(k_{0}\right)\right] d F(V) \\
& +\int_{V_{1}}^{\bar{V}}\left[\left(1-\theta_{2} \lambda\right)\left(1+k_{2}\right) V-\rho-C\left(k_{2}\right)\right] d F(V)
\end{aligned}
$$


The socially optimal pricing vector $\langle R, Q\rangle$ is different from before, that is, $\langle r / \lambda, \rho / \lambda\rangle$, since prices should also reflect the fact that each system is associated with different levels of land improvement. Recording and registration are associated with higher capital improvements and thus generate more value than privacy.

Given the socially optimal prices, if recording has the lowest critical value $\left(V_{0} \leq V_{1}\right)$, recording should be preferred to registration if and only if it produces greater social welfare:

$$
\begin{aligned}
& W^{r c}-W^{r g}= \\
& \int_{V_{0}}^{V_{1}}\left\{\left[\left(1-\theta_{1} \lambda\right)\left(1+k_{1}\right)-\left(1-\theta_{0} \lambda\right)\left(1+k_{0}\right)\right] V-r+C\left(k_{0}\right)-C\left(k_{1}\right)\right\} d F(V) \\
+ & \int_{V_{1}}^{\bar{V}}\left\{\left[\left(1-\theta_{1} \lambda\right)\left(1+k_{1}\right)-\left(1-\theta_{2} \lambda\right)\left(1+k_{2}\right)\right] V\right. \\
& \left.+\rho-r+C\left(k_{2}\right)-C\left(k_{1}\right)\right\} d F(V) \geq 0
\end{aligned}
$$

Yet, if registration has the lowest critical value $\left(V_{0}>V_{1}\right)$, recording is never preferred to registration because:

$$
\begin{aligned}
& W^{r c}-W^{r g}= \\
& \int_{V_{1}}^{V_{0}}\left\{\left[\left(1-\theta_{0} \lambda\right)\left(1+k_{0}\right)-\left(1+k_{2}\right)\right] V+\rho+C\left(k_{2}\right)-C\left(k_{0}\right)\right\} d F(V) \\
+ & \int_{V_{1}}^{\bar{V}}\left\{\left[\left(1-\theta_{1} \lambda\right)\left(1+k_{1}\right)-\left(1-\theta_{2} \lambda\right)\left(1+k_{2}\right)\right] V\right. \\
& \left.+\rho-r+C\left(k_{2}\right)-C\left(k_{1}\right)\right\} d F(V)<0
\end{aligned}
$$

In (11), the first term is positive: a recording system is better for these parcels of land because under a registration system, only privacy takes place. It is reinforced by the fact that investment in land improvements is lowest under privacy. The last term is negative because highly valuable parcels 
of land should be registered rather than recorded. Again notice that this effect is also reinforced because investment is highest under registration and not under recording. In (12), the two terms are negative: registration is unambiguously preferred to recording.

\section{Appendix C: Formal Model with Adverse Se- lection}

We develop here a model of adverse selection for land transactions under different titling systems. The hidden information underlying the adverse selection problem is the standing of the land title, that is, we assume that the seller has better information than the buyer concerning the marginal cost of forfeiture due to future claims. The buyer knows that $\theta_{i}$, where $i=$ $0,1,2$ stands for privacy, recording and registration respectively, is uniformly distributed in the interval $\left[0, \bar{\theta}_{i}\right]$. Furthermore $0<\bar{\theta}_{2}<\bar{\theta}_{1}<\bar{\theta}_{0}<1$, that is, the highest marginal cost of forfeiture is greater under privacy than under recording, and lower under registration. The probability density function is $1 / \bar{\theta}_{i}$ and the cumulative density function is $\theta_{i} / \bar{\theta}_{i}$. The expected value of the distribution is $\bar{\theta}_{i} / 2$, that is, on average, we expect a higher marginal forfeiture cost under privacy than under recording or registration.

The buyer values the parcel of land of $V^{B}$ and the seller values the same parcel of land of $V^{S}$, with $V^{S}<V^{B}$, both common knowledge. We also assume that $\left(1-\bar{\theta}_{i} / 2\right) V^{B}<V^{S}<V^{B}<2 V^{S}$ since, otherwise, there would be no adverse selection problem, the buyer would be willing to pay $V^{S}$ and the seller would always be willing to sell.

The price $P$ is offered by the buyer to the seller in a competitive market (therefore, a zero profit constraint will be imposed as a participation constraint for the buyer) with hidden information. The expected payoff for the risk neutral seller is $P-\left(1-\theta_{i}\right) V^{S}$. Given the price $P$, the seller accepts 
the offer as long as $\theta_{i}$ is greater than $1-P / V^{S}$. Here we can see the adverse selection problem. For a given $P$ offered by the buyer, the seller is only willing to sell if the marginal cost of forfeiture (unknown for the buyer) is reasonably high. Parcels of land with high quality titles will not be traded, unless of course $P=V^{S}$.

The expected payoff for the buyer is given by $\left(1-\theta_{i}^{a}\right) V^{B}-P$, where $\theta_{i}^{a}$ is the expected marginal cost of forfeiture conditioned on an offer being accepted by the seller. The average expected marginal cost of forfeiture is therefore:

$$
\theta_{i}^{a}=\frac{1+\bar{\theta}_{i}-P / V^{S}}{2}
$$

By substituting for $\theta_{i}^{a}$ in the expected payoff for the buyer and imposing a zero-profit constraint, we obtain the following condition for the price $P$ :

$$
\left(1-\bar{\theta}_{i}+P / V^{S}\right) V^{B} / 2-P=0
$$

Solving for the price $P$, the price and average expected marginal cost of forfeiture become:

$$
\begin{aligned}
P & =\frac{\left(1-\bar{\theta}_{i}\right) V^{B}}{2-V^{B} / V^{S}} \\
\theta_{i}^{a} & =\frac{1+\bar{\theta}_{i}-V^{B} / V^{S}}{2-V^{B} / V^{S}}
\end{aligned}
$$

From the definition of $P$, we can state the following results for a given pair of land valuations for buyer and seller, $V^{B}$ and $V^{S}$ respectively: (1) Prices will be highest for registered, in between for recorded, and lowest for privately held land; (2) The average expected marginal cost of forfeiture is highest for privately held, in between for recorded, and lowest for registered land; (3) The adverse selection problem will be less marked for registered, in between for recorded, and most marked for privately held land. 
Figure 1. Private utility as a function of the value of land under different titling solutions

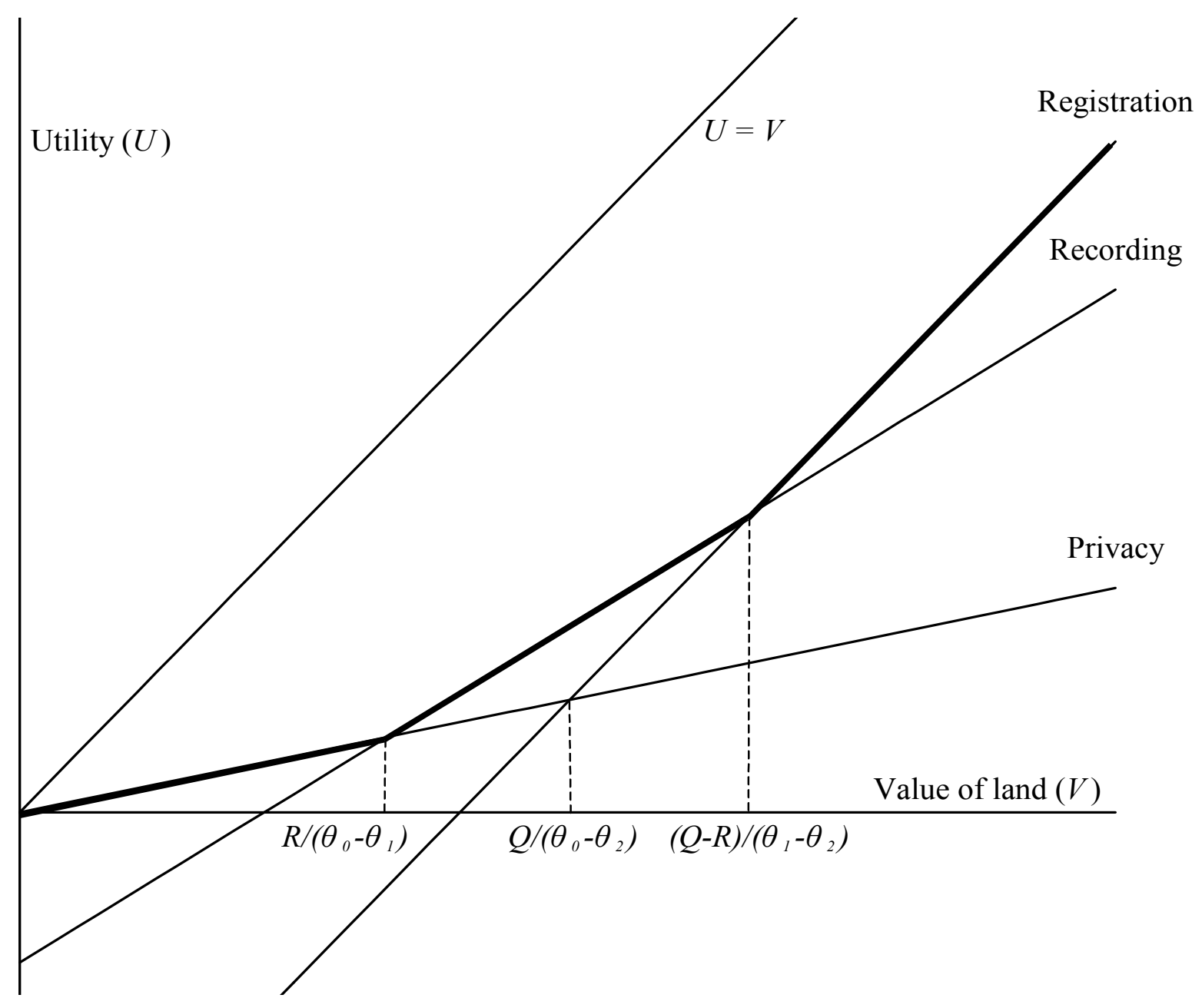


Figure 2. Social welfare as a function of the value of land under different titling solutions when $V_{1}>V_{0}$

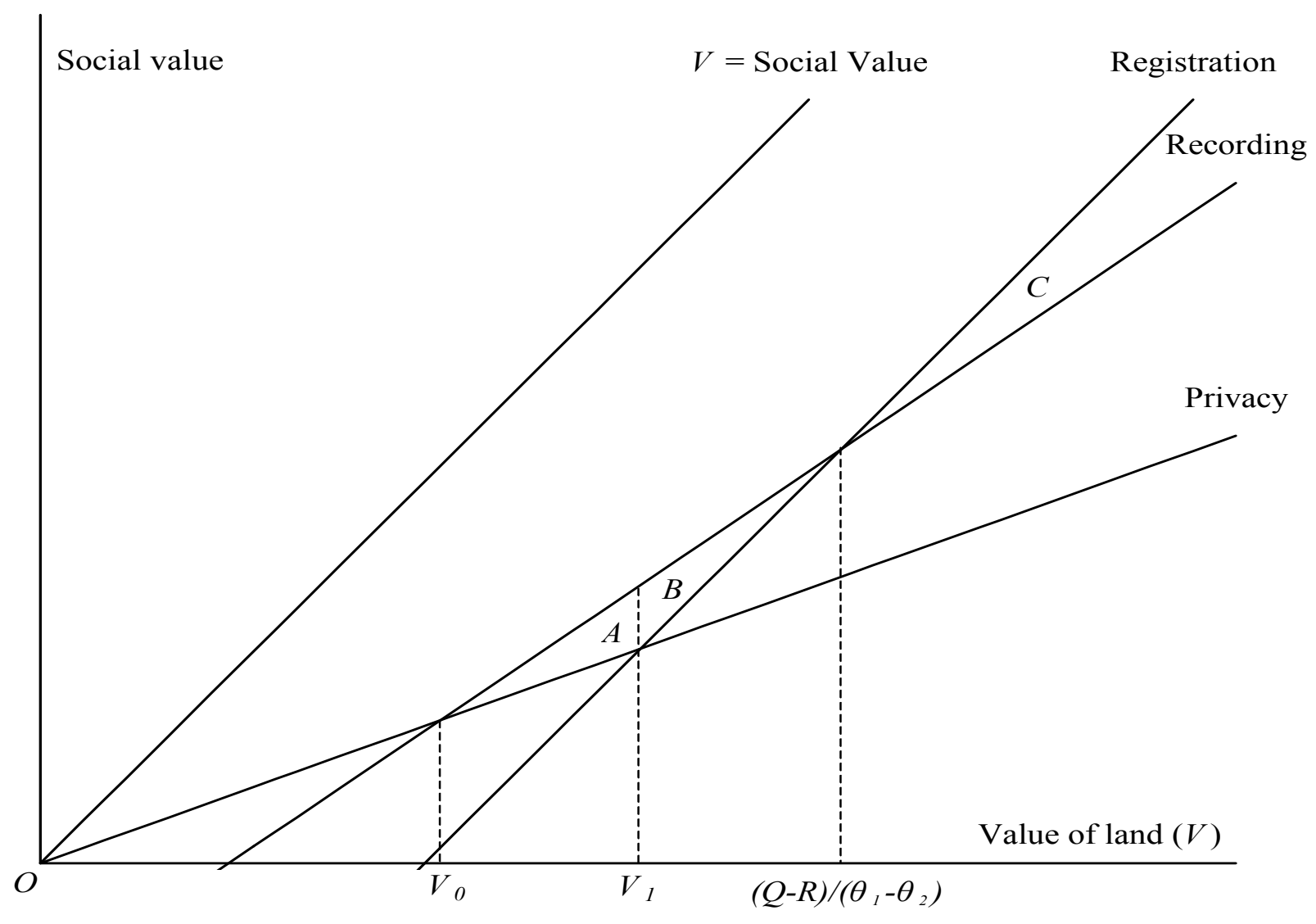


Figure 3. Social welfare as a function of the value of land under different titling solutions when $V_{0}>V_{1}$

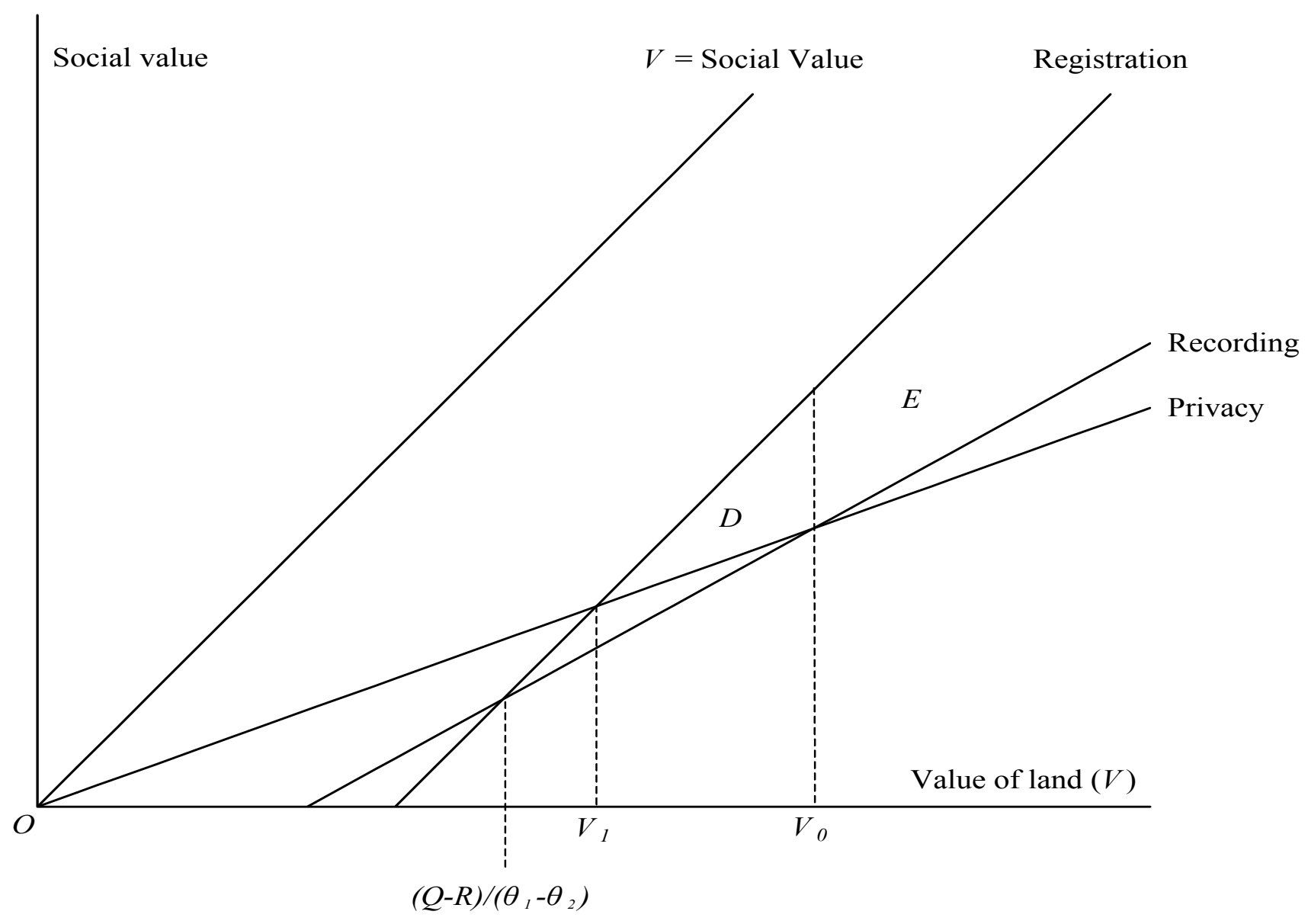


Table 1. Summary of Figure 2

\begin{tabular}{|l|c|c|c|c|}
\hline & 0 to $V_{0}$ & $V_{0}$ to $V_{I}$ & $\begin{array}{c}V_{1} \text { to } \\
(P-R) /\left(\theta_{I}-\theta_{2}\right)\end{array}$ & $\begin{array}{c}(P-R) /\left(\theta_{1}-\theta_{2}\right) \\
\text { to highest } V\end{array}$ \\
\hline $\begin{array}{l}\text { Optimal titling } \\
\text { regime in each } \\
\text { segment }\end{array}$ & Privacy & Recording & Recording & Registration \\
\hline $\begin{array}{l}\text { Titling decision } \\
\text { given recording }\end{array}$ & Privacy & Recording & Recording & Recording \\
\hline $\begin{array}{l}\text { Titling decision } \\
\text { given registration }\end{array}$ & Privacy & Privacy & Registration & Registration \\
\hline $\begin{array}{l}\text { Gain from choos- } \\
\text { ing registration } \\
\text { over recording }\end{array}$ & 0 & $-A$ & $-B$ & $+C$ \\
\hline
\end{tabular}

Table 2. Summary of Figure 3

\begin{tabular}{|l|c|c|c|}
\hline & 0 to $V_{l}$ & $V_{I}$ to $V_{0}$ & $V_{0}$ to highest $V$ \\
\hline $\begin{array}{l}\text { Optimal titling regime } \\
\text { in each segment }\end{array}$ & Privacy & Registration & Registration \\
\hline $\begin{array}{l}\text { Titling decision given } \\
\text { recording }\end{array}$ & Privacy & Privacy & Recording \\
\hline $\begin{array}{l}\text { Titling decision given } \\
\text { registration }\end{array}$ & Privacy & Registration & Registration \\
\hline $\begin{array}{l}\text { Gain from choosing } \\
\text { registration over } \\
\text { recording }\end{array}$ & 0 & $D$ & $E$ \\
\hline
\end{tabular}

